\title{
Efficacy and safety of meropenem in the treatment of antimicrobial-resistant post-operative chest infections:
} a case series

\author{
Kelechi Martins Nworie ${ }^{1,2}$, Deborah Oyine Aluh ${ }^{1,2}$, Joseph Adimegwu ${ }^{3}$, Obinna Felix Dim ${ }^{1}$
}

\author{
${ }^{1}$ Department of Clinical Pharmacy and Pharmacy Management, University of Nigeria, \\ Nsukka, Nigeria \\ 2Pharmaceutical Outcomes Research Group, Faculty of Pharmacy, \\ University of Nigeria, Nsukka, Nigeria \\ ${ }^{3}$ Department of Pharmacy, Memfys Hospital for Neurosurgery, Enugu, Nigeria
}

Submitted: 19 February 2018

Accepted: 24 March 2018

Arch Med Sci Aging 2018; 1: e3-e7

DOI: https://doi.org/10.5114/aoms.2018.74982

Copyright @ 2018 Termedia \& Banach

\section{Abstract}

Introduction: Meropenem is a $\beta$-lactam ultra-broad spectrum injectable antibiotic used to treat a wide variety of infections. Its effectiveness and safety in antimicrobial-resistant infections have been scarcely assessed in African patients. This study evaluated the outcomes and adverse effects associated with the use of meropenem for the treatment of antimicrobial-resistant post-operative chest infections.

Material and methods: The study was conducted at Memfys Hospital for Neurosurgery, a specialist hospital in Enugu, Nigeria. Between September and November 2017, a total of 32 patients (aged above 50 years) presented with an episode of chest infection 24-48 h after an operative procedure. Twenty-eight of these patients were prescribed ceftriaxone and other suppressive antibiotics as first-line treatment. Seven of these patients presented with antimicrobial resistance and were subsequently treated with meropenem and were considered to meet the criteria for the study. Sputum culture, white cell count and axillary temperature were obtained for diagnostic guidance in all patients.

Results: The mean age was $61 \pm 9$ years, 6 were male, all patients were HIV and tuberculosis negative, 1 patient was diabetic, another had an ulcer and another was hypertensive. Regarding outcomes, all patients were completely treated for chest infection complications. However, a mild side effect was observed in 1 patient.

Conclusions: Meropenem is an effective and safe antibiotic as evidenced by bacterial culture and the mild adverse effect profile in post-operative patients with antimicrobial-resistant infections.

Key words: infection, safety, resistance, efficacy, meropenem, antimicrobial.

\section{Introduction}

There is commonly a risk of a patient developing infection after a surgical operation [1], and the incidence of this occurrence after surgery under general anesthetics varies between $17 \%$ and $18 \%$ [2]. General anesthetics and surgery negatively interfere with the normal way the lungs remove secretions (phlegm). Pain from the surgery can also make breath-

\author{
Corresponding author: \\ Kelechi Martins Nworie \\ Department of \\ Clinical Pharmacy \\ and Pharmacy Management \\ University of Nigeria \\ 410001 Nsukka, Nigeria \\ Phone: +234 (0) 8063728781 \\ Email: \\ nworiekelechimartins@gmail. \\ com
}


ing and productive coughing difficult. These may lead to development of an infection within the phlegm. The bacteria commonly associated with this infection, particularly Staph spp. and Coliforms (according to this study), may be controversially accepted as part of the oropharyngeal flora [3]. Therefore, the presence of these potential pathogens in the oropharynx before an operation might be related to the development of chest infection after surgery. Post-operative chest infections are usually treated in the hospital with antibiotics. These agents may be given as oral therapy, but intra-venous delivery is preferred in severe infections. First-line treatments are mostly 5-day courses of amoxicillin, a macrolide (e.g. erythromycin, clarithromycin, azithromycin, for those who are allergic to penicillin) or cephalosporins (e.g. cefuroxime or ceftriaxone) [4]. Although these antibiotics provide an excellent broad spectrum effect, they require multiple dose therapy (possibly associated with multiple side effects), which can sometimes be inconvenient to patients (leading to no-compliance) and have a possibility of developing drug resistance [5]. Meropenem is an ultra-broad spectrum injectable antibiotic, a $\beta$-lactam belonging to the carbapenem subgroup. It penetrates well into many tissues and body fluid, including cerebrospinal fluid (CSF), bile, heart valve, lungs, and peritoneal fluids [6]. It is bactericidal except against Listeria monocytogenes, where it is bacteriostatic. In contrast to other $\beta$-lactams, it is highly resistant to degradation by $\beta$-lactamase or cephalosporinases. Therefore, given the wide tissue distribution, bioavailability, ease of administration, and degradation resistance, meropenem may be a very effective drug for treating severe infections.

The problem of antimicrobial resistance is currently a world-wide medical and public health concern [7]. Antimicrobial resistant organisms after use of cephalosporins are perceived to be on the increase. Normal practice is to use meropenem and its congeners if available, to manage these resistant strains post-operatively. There is however little literature evidence to show meropenem's efficacy and safety in such cases in hospital settings in de-

Table I. Criteria or symptoms for chest infection [1]

\begin{tabular}{|lc|}
\hline Temperature & $>36.8^{\circ} \mathrm{C}>24 \mathrm{~h}$ after operation \\
\hline Cough & $\begin{array}{c}\text { Developed or increased since } \\
\text { operation }\end{array}$ \\
\hline Sputum culture & Positive \\
\hline Examination & Crackles or wheezes \\
\hline White blood cell count & $11 \times 10^{9} \mathrm{~g} / \mathrm{l}$ \\
\hline Total of 4 or more criteria present indicates chest \\
infection;
\end{tabular}

veloping countries. Therefore, this study evaluated the efficacy and safety profile of meropenem as therapy for antimicrobial-resistant post-operative chest infections in a Nigerian specialist hospital.

\section{Material and methods}

\section{Study design and eligibility}

Patients diagnosed with antimicrobial resistant post-operative chest infection at the Memfys Hospital for Neurosurgery, a specialist and tertiary hospital in Enugu, South Eastern Nigeria, between October and November 2017 were included in this study. Ethical approval to conduct this study was obtained from the institutional ethics committee.

The overall study population comprised patients diagnosed with post-operative infection and who had undergone a course of antibiotic therapy, which included ceftriaxone as first-line treatment in concomitance with other suppressive antibiotics if the drug sensitivity test (DST) showed sensitivity to these drugs and resistance was diagnosed. However, patients included in this study were those diagnosed with an episode of ceftriaxone resistance.

\section{Criteria for infection}

Presence of infection was indicated by the clinical criteria for diagnosis of post-operative chest infection (Table I). These criteria include: temperature $>36.8^{\circ} \mathrm{C}$, development of cough, crackles and wheezes on examination, white blood cells (WBC) count $>11 \times 10^{9} \mathrm{~g} / \mathrm{l}$, and positive sputum culture [1]; and one or more of the following: positive blood culture, suggestive radiographic findings on chest X-ray scan, increased purulence of sputum, or faster heart rate. Patients who responded fully to ceftriaxone treatment were excluded from the study.

\section{Treatment protocol for post-operative infection}

At the initial episode of chest infection, i.e. 24-48 $\mathrm{h}$ after the surgical operation (Table II), patients were placed on ceftriaxone $1 \mathrm{~g}$ every $8 \mathrm{~h}$ in combination with other suppressive antibiotics which showed susceptibility. In the event of therapeutic failure at the end of ceftriaxone therapy, the first-line drugs were withdrawn and the patients were placed on meropenem in the second phase of treatment. The outcomes at the end of each episode therapy were also assessed through the clinical observation chart reviews. Success of treatment was defined as resolution of clinical signs and symptoms of infection such that discontinuation of antibiotics was deemed appropriate with no recurrence; failure was defined as the per- 
Table II. Demographics and clinical status of patients $24-48 \mathrm{~h}$ after surgical operation

\begin{tabular}{|lccccccc|}
\hline Patient & $\begin{array}{c}\text { Age } \\
{[\text { years }]}\end{array}$ & Gender & $\begin{array}{c}\text { Temperature } \\
{\left[{ }^{\circ} \mathrm{C}\right]}\end{array}$ & Cough & Chest examination & WBC $[\mathrm{g} / \mathrm{l}]$ & Sputum culture \\
\hline 1 & 54 & Male & 38.7 & Yes & Crackle, wheezes & $20.0 \times 10^{9}$ & Staph spp. \\
\hline 2 & 51 & Male & 39.1 & None & Crackles & $19.0 \times 10^{9}$ & Coliform \\
\hline 3 & 52 & Female & 39.9 & Yes & Crackles & $21.0 \times 10^{9}$ & Staph spp. \\
\hline 4 & 64 & Male & 39.6 & Yes & Crackles, wheezes & $21.0 \times 10^{9}$ & Coliform \\
\hline 5 & 68 & Male & 38.7 & None & Crackles & $23.0 \times 10^{9}$ & Staph spp. \\
\hline 6 & 71 & Male & 40.1 & Yes & Crackles & $19.0 \times 10^{9}$ & Coliform \\
\hline 7 & 69 & Male & 40.8 & None & Crackles, wheezes & $20.0 \times 10^{9}$ & Staph spp. \\
\hline
\end{tabular}

WBC - white blood cell.

sistence or progression of symptoms [8]. Patients' records such as demographic and clinical data, drug administration information, outcomes and adverse effects were collected on a standardized case report form. For clarification and accuracy of data collection and analysis in the study, each patient was assigned a unique study number. Data were collected carefully, and archived in a tamper-proof database.

\section{Results}

\section{Patients' characteristics}

A total of 32 patients were diagnosed with chest infection 24-48 $\mathrm{h}$ after the surgical operation. Twenty-eight of these patients were identified to have received ceftriaxone and other suppressive antibiotics as first-line treatment during their stay at the hospital. Four patients were excluded from the study because their medical treatment and laboratory charts could not show complete clinical data required for the study. Of these 28 patients, 19 had a successful treatment with ceftriaxone and other adjunct antibiotics. Of the remainder, 9 patients presented with ceftriaxone resistance, 2 who were diagnosed with severe sepsis were treated with piperacillin/tazobactam, and 7 patients were treated with meropenem alone.

Mean age of the 7 patients was $61 \pm 9$ years and the majority (85.7\%) were male. Common comorbidities included ulcer (14.3\%), hypertension $(14.3 \%)$, diabetes $(14.3 \%)$ and history of alcohol (71.4\%). All patients were non-smokers and had no history of chronic bronchitis or chronic airway obstruction. Most of the surgical diagnoses were cranial-related problems (57.1\%) while others (42.9) were spine related. Surgical intervention was pursued in all patients. Onset of clinical symptoms of chest infection occurred 24 h $(71.4 \%)$ and 48 h (28.6\%) after the surgical operation. Some patients (57.1\%) had a significant level of consciousness, cough, wheezes and crack- les; all patients had fever and a high WBC count of more than $36.8^{\circ} \mathrm{C}$ and $11 \times 10^{\circ} \mathrm{g} / /$ respectively. Organisms obtained from sputum culture included Staph spp. (57.1\%), and Coliform (42.9\%).

\section{Patients' clinical outcomes after treatment protocols}

In the initial treatment protocol, patients received 5 days of treatment doses of ceftriaxone $1 \mathrm{~g}$ every $8 \mathrm{~h}$ in combination with other suppressive antibiotics. Although the symptoms seemed to have attenuated in 9 patients at the end of treatment, it did not meet the criteria set for "no chest infection' according to the study. Therefore, the clinical outcome of ceftriaxone in these 9 patients was concluded a failure (Table III).

In the second treatment protocol, 7 of the patients who presented with ceftriaxone resistance received meropenem for a duration of 3 days with dosage according to severity of infection. In one case (patient 1), a patient who had a sudden onset of severe low back pain (LBP) 3 days prior to hospital admission was diagnosed with spinal complications. He developed chest infection $24 \mathrm{~h}$ after the operation; however, he continued to have symptoms at the end of ceftriaxone intravenous therapy and was given meropenem $1 \mathrm{~g}$ stat and $500 \mathrm{mg}$ every $8 \mathrm{~h}$. Clinical success was achieved after 3 days and all antibiotics were discontinued (Table IV). The second case (patient 2) was a hypertensive patient diagnosed with subarachnoid hemorrhage. He developed chest infection $48 \mathrm{~h}$ after surgery and continued to show symptoms of infection at the end of ceftriaxone intravenous therapy. He was subsequently given meropenem $1 \mathrm{~g}$ every $12 \mathrm{~h}$; clinical success was achieved after 3 days and the antibiotic was withdrawn. In the third case (patient 3), a patient who had surgical intervention for significant cerebrospinal fluid pressure and continued to have symptoms of chest infection at the end of ceftriaxone therapy, was subsequently given meropenem $1 \mathrm{~g}$ every 
Table III. Clinical outcomes of patients treated with ceftriaxone

\begin{tabular}{|c|c|c|c|c|c|c|c|c|}
\hline Patient & $\begin{array}{c}\text { Duration } \\
\text { on CT } \\
\text { [days] }\end{array}$ & $\begin{array}{c}\text { Temperature } \\
{\left[{ }^{\circ} \mathrm{C}\right]}\end{array}$ & Cough & $\begin{array}{c}\text { Chest } \\
\text { examination }\end{array}$ & WBC $[\mathrm{g} / \mathrm{l}]$ & $\begin{array}{l}\text { Sputum } \\
\text { culture }\end{array}$ & $\begin{array}{l}\text { Other adjunct } \\
\text { antibiotics }\end{array}$ & $\begin{array}{l}\text { Clinical } \\
\text { outcome }\end{array}$ \\
\hline 1 & 5 & 38.1 & Yes & Wheezes & $16.0 \times 10^{9}$ & Staph spp. & $\begin{array}{l}\text { Levofloxacin in } \\
\text { combination } \\
\text { with CT }\end{array}$ & Failure \\
\hline 2 & 6 & 37.8 & None & Crackles & $19.0 \times 10^{9}$ & Coliform & $\begin{array}{c}\text { Metronidazole } \\
\text { prior to } \mathrm{CT}\end{array}$ & Failure \\
\hline 3 & 5 & 37.4 & Yes & Wheezes & $17.0 \times 10^{9}$ & Staph spp. & $\begin{array}{l}\text { Streptomycin } \\
\text { combination } \\
\text { with CT }\end{array}$ & Failure \\
\hline 4 & 5 & 38.3 & Yes & $\begin{array}{l}\text { Wheezes, } \\
\text { crackles }\end{array}$ & $19.0 \times 10^{9}$ & Coliform & $\begin{array}{c}\text { Levofloxacin in } \\
\text { combination } \\
\text { with CT }\end{array}$ & Failure \\
\hline 5 & 5 & 38.5 & None & $\begin{array}{l}\text { Wheezes, } \\
\text { crackles }\end{array}$ & $21.0 \times 10^{9}$ & Staph spp. & $\begin{array}{c}\text { Levofloxacin in } \\
\text { combination } \\
\text { with CT }\end{array}$ & Failure \\
\hline 6 & 6 & 38.7 & Yes & $\begin{array}{l}\text { Wheezes, } \\
\text { crackles }\end{array}$ & $19.0 \times 10^{9}$ & Coliform & $\begin{array}{c}\text { Levofloxacin in } \\
\text { combination } \\
\text { with CT }\end{array}$ & Failure \\
\hline 7 & 5 & 38.9 & Yes & Wheezes & $18.0 \times 10^{9}$ & Staph spp. & $\begin{array}{c}\text { Ciprofloxacin } \\
\text { in combination } \\
\text { with CT }\end{array}$ & Failure \\
\hline
\end{tabular}

CT - ceftriaxone; WBC: white blood cell; Success - defined as resolution of clinical signs and symptoms of infection, and clear infection on sputum culture test; Failure - defined as any case not meeting criteria for success.

Table IV. Clinical outcomes of ceftriaxone-resistant patients treated with meropenem

\begin{tabular}{|lcclllll|}
\hline Patient & $\begin{array}{c}\text { Duration } \\
\text { on } \mathrm{MEM} \\
{[\text { days }]}\end{array}$ & $\begin{array}{c}\text { Temperature } \\
{\left[{ }^{\circ} \mathrm{C}\right]}\end{array}$ & Cough & $\begin{array}{c}\text { Chest } \\
\text { examination }\end{array}$ & WBC $[\mathrm{g} / \mathrm{l}]$ & $\begin{array}{c}\text { Sputum } \\
\text { culture }\end{array}$ & $\begin{array}{c}\text { Clinical } \\
\text { outcome }\end{array}$ \\
\hline 1 & 3 & 36.7 & None & None & $9.0 \times 10^{9}$ & None & Success \\
\hline 2 & 3 & 36.9 & None & None & $8.0 \times 10^{9}$ & None & Success \\
\hline 3 & 4 & 36.8 & None & None & $12.0 \times 10^{9}$ & None & Success \\
\hline 4 & 3 & 36.9 & Yes & None & $11.0 \times 10^{9}$ & None & Success \\
\hline 5 & 3 & 36.7 & None & None & $8.0 \times 10^{9}$ & None & Success \\
\hline 6 & 3 & 36.8 & None & None & $9.0 \times 10^{9}$ & None & Success \\
\hline 7 & 3 & 36.7 & None & None & $7.0 \times 10^{9}$ & None & Success \\
\hline
\end{tabular}

MEM - meropenem, WBC - white blood cell, Success - defined as resolution of clinical signs and symptoms of infection, and clear infection on sputum culture test, Failure - defined as any case not meeting criteria for success.

$12 \mathrm{~h}$ and later $500 \mathrm{mg}$ every $12 \mathrm{~h}$ in combination with ciprofloxacin 500 mg every 12 h. Clinical success was achieved after 4 days and all antibiotics were stopped (Table IV).

In summary, all patients achieved clinical success after the second treatment protocol (Table IV). Nonetheless, there was an occurrence of a side effect in case 3 - a 52-year-old woman who developed mild rashes in the neck region after 2 days of administration of meropenem. This led to administered dose reduction from $1 \mathrm{~g} 12$ hourly to $500 \mathrm{mg} 12$ hourly. The rashes disappeared after 7 days and she was considered a clinical success at the end of therapy.

\section{Discussion}

Medication and drug use evaluation is a method of evaluating and ensuring the appropriate use of drugs. It is a method for attaining information to improve rational drug therapy in the clinical setting $[9,10]$. While drug use evaluation ensures that medicines are used appropriately, medication use evaluation emphasizes improving patients' outcomes and individual quality of life. However, both promote optimal medication therapy and ensure that drug therapy meets current standard of care. Drug use review could access the entire process of medication use, including indications, 
dose and route of administration, treatment duration, drug interaction and outcomes [10]. Thus, the study was conceived and adopted from the concept of the WHO to evaluate the use and outcome of a therapeutic indication.

In the series, we presented 7 cases of antimicrobial-resistance post-operative chest infection treated with meropenem. Our results showed a $100 \%$ success rate among patients on an average duration of 3 days of therapy. In a similar study evaluating the use of meropenem in septic patients, the success rate was found to be more than $80 \%$ [11].

Since all the first-line antimicrobials failed, meropenem was given alone as monotherapy except in one case. Since all patients were clear of infection at the end of meropenem therapy, this suggests that meropenem may not require an antimicrobial adjunctive for clinical intervention of especially post-operative chest infections. However, 1 patient had an occurrence of a side effect which could be attributed to mild drug allergy. The patient had a reduction in the dose of meropenem and was also clear of infection at the end of therapy.

While it was noted that we set criteria for presence or absence of chest infection, we also had an ultimate conclusion with the sputum culture test. This is likely a common test used in hospitals in Nigeria which do not have access to modern X-ray technology for the diagnosis of chest infection; however, whether it is an adequate or accurate method calls for further study. Outcomes of treatment (e.g. temperature, white cell count) were monitoring parameters for ascertaining cleared infection.

The main limitation of this study was assessing a small sample of study subjects. We included only 7 patients for use of meropenem in treatment of antimicrobial-resistant post-operative chest infection. This sample population seemed small and may present a possibility of an incomplete or inadequate conclusion of the outcomes associated with the use of meropenem. However, owing to the fact that this study was set in a sizeable hospital, the small group of patients may not fully reflect the outcome of meropenem use in a larger population or different setting [11]. Nonetheless, the study shows efficacy and an appreciable safety outline for meropenem use in mild or severe antimicrobial-resistant post-operative chest infection. Thus, the information or data from this study are explicitly useable for the treatment of antimicrobial-resistant post-operative chest infections in a clinical or hospital setting.

In conclusion, according to our results, meropenem has been proven to be a very effective and safe antibiotic; thus it should be adopted as treat- ment for complicated post-operative chest infections. It should be encouraged in severe infections and situations where chances are not to be taken.

A further study with a larger sample group should be conducted to appropriately access the side effects associated with meropenem use in a hospital setting. Finally, this study will help and prove useful to medical practitioners in both clinical and hospital settings.

\section{Conflict of interest}

The authors declare no conflict of interest.

\section{References}

1. Dilworth JP, White RJ, Brown EM. Oropharyngeal flora and chest infection after upper abdominal surgery. Thorax 1991; 46: 165-7.

2. Whightman JAK. A prospective survey of the incidence of postoperative pulmonary complications. $\mathrm{Br}$ J Surg 1968; 55: 85-91.

3. Smith AJ, Jackson MS, Bagg J. The ecology of staphylococcus species in the oral cavity. J Med Microbiol 2001; 50: 940-6.

4. Marshall S. Chest infection in the community. Pharmaceut J 2007; 279: 475-8.

5. Richardson LA. Understanding and overcoming antibiotic resistance. PLoS Biol 2017; 15: e2003775

6. Byl B, Jacobs F, Roucloux I, de Franquen P, Cappello M, Thys JP. Penetration of meropenem in lungs, bronchial mucosa, and pleural tissues. Antimicrob Agents Chemother 1999; 43: 681-2.

7. Balode A, Punda-Polic V, Dowzicky MJ. Antimicrobial susceptibility of Gram-negative and Gram-positive bacteria collected from countries in Eastern Europe: results from the Tigecycline Evaluation and Surveillance Trial (T.E.S.T) 2004-2010. Int J Antimicrob Agents 2013; 41: 527-35.

8. Goswami ND, Johnson MD, Chu VH. Ertapenem for treatment of osteomyelitis: a case series. BMC Research Notes 2011; 4: 478.

9. Nadzam DM. Development of medication-use indicators by the Joint Commission on Accreditation of Healthcare Organizations. Am J Hosp Pharm 1991; 48: 1925-30.

10. World Health Organization. Introduction to drug utilization research. World Health Organiation, Oslo, 2003.

11. Sumret W, Saowakul K, Haephruk T, Pengsombat P, Kwanmuang W, Wichai S. Evaluation of meropenem use among septic patients at HuaHin Hospital, Thailand. Silpakorn U Science Tech J 2016; 10: 21-6. 